\title{
HYPOPITUITARISM IN A MALE DUE TO GIANT CELL GRANULOMA OF THE ANTERIOR PITUITARY
}

\author{
BY \\ M. H. OELBAUM AND J. WAINWRIGHT \\ From the Manchester Royal Infirmary and the Department of Pathology. \\ University of Manchester
}

(RECEIVED FOR PUBLICATION FEBRUARY 15, 1950)

It has been emphasized by Sheehan (1948) that the criterion for the diagnosis of hypopituitarism is destruction of the anterior pituitary, the most frequent cause being post-partum necrosis. Hypopituitarism in the male is relatively uncommon. Escamilla and Lisser (1942), in a survey of 101 " typical clinical cases with pathological verification," found only 35 in the male.

The following case, which was fully investigated clinically, is reported because of the unusual pathological lesion in the pituitary.

\section{Case Report}

The patient, a man aged 29 years, was admitted to the Manchester Royal Infirmary under the care of Dr. C. S. D. Don on August 3, 1948. He had been under the care of Dr. F. Janus at the Manchester Royal Eye Hospital, on account of blurring of vision and pain in the left eye. These symptoms were of three months' duration and the diagnosis made was interstitial keratitis and iritis of the left eye. In addition there were vitreous opacities and an old anterior choroiditis in the right eye.

He also complained of weakness during the past two years; this was rapidly becoming more severe so that he was unable to carry on any occupation. On close questioning it was further elicited that during this period he had noted an increasing sensitivity to cold and loss of libido, with infrequent erections and no emissions in the last 18 months. Pubic and axillary hair had been lost. More recently he had had anorexia and vomiting, and had lost $6 \mathrm{lb}$. in weight. For six months there had been occasional transient attacks of sweating, but no accompanying disturbance of consciousness.

The patient was married at 23 , and had a healthy child aged 5 years. A second child, two years later, died at 10 days from "lung trouble." The patient's mother, aged 69, was blind and demented. His two brothers and two sisters were healthy.

Clinical Examination.-On admission he was thin, but normally proportioned (height, 62 in., weight, 114 lb.). His intelligence was moderate; speech, comprehension, and movement were all rather slow. The skin was smooth with a peculiar waxy pallor, but the mucous membranes were of normal colour. There was no abnormal pigmentation. The hair was dark and plentiful on the head and eyebrows, 
very scanty in the pubic region, and absent in both axillae. Body hair was almost completely absent, and although the patient had not shaved for a week there was little beard.

The left eye showed a ground-glass opacity of the cornea (Fig. 1), with a blepharoconjunctivitis. The left upper central incisor tooth was barrel-shaped, with notching and narrowing at the cutting edge (Fig. 2). The rest of the teeth were normal apart from dental caries. There was no deafness.

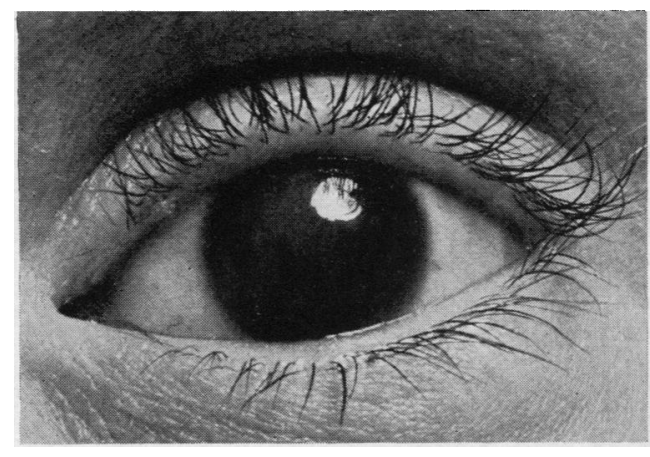

FIG. 1.-Left eye showing ground glass opacity of cornea.

Fig. 2.-Barrel-shaped left upper central incisor, with narrowing and notching of cutting edge.

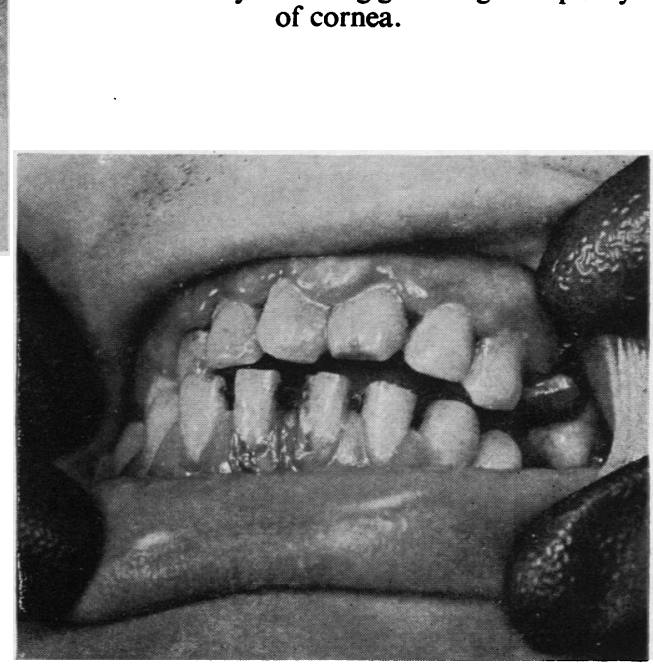

No abnormal signs were found in the chest, abdomen, and nervous system. The pulse rate was 62 , and the blood pressure $95 / 75 \mathrm{~mm}$. $\mathrm{Hg}$. The penis and testes were small.

Laboratory Investigations.-A blood count showed : red cells, 4,380,000/mm. ; haemoglobin 11.6 g./100 ml. ; colour index 0.95 ; white cells $9,400 /$ c.mm. (7.5\% eosinophils).

Blood Wassermann and Kahn reactions: negative.

Cerebrospinal fluid: 8 lymphocytes $/$ c.mm. ; protein $50 \mathrm{mg}$. \% ; slight globulin opalescence; Lange curve normal; Wassermann negative.

Mantoux reaction: positive.

Basal metabolic rate: $-30 \%$.

$X$-ray examination of the skull, chest, and epiphyses, all normal.

Kepler test : positive. $\left\{\begin{array}{c}\text { Volume of night urine: } 134 \mathrm{ml} \\ \text { Maximum hourly specimen: } 31 \mathrm{ml} . \\ \text { Plasma chloride: 491 mg. } \% \text { Blood urea: } 20 \mathrm{mg} . \% \\ \text { Urinary chloride: } 538 \mathrm{mg} \% \\ \text { Urinary urea }: 2.2 \mathrm{~g} . \% \\ \text { Mayo Clinic factor: } 23\end{array}\right.$ 


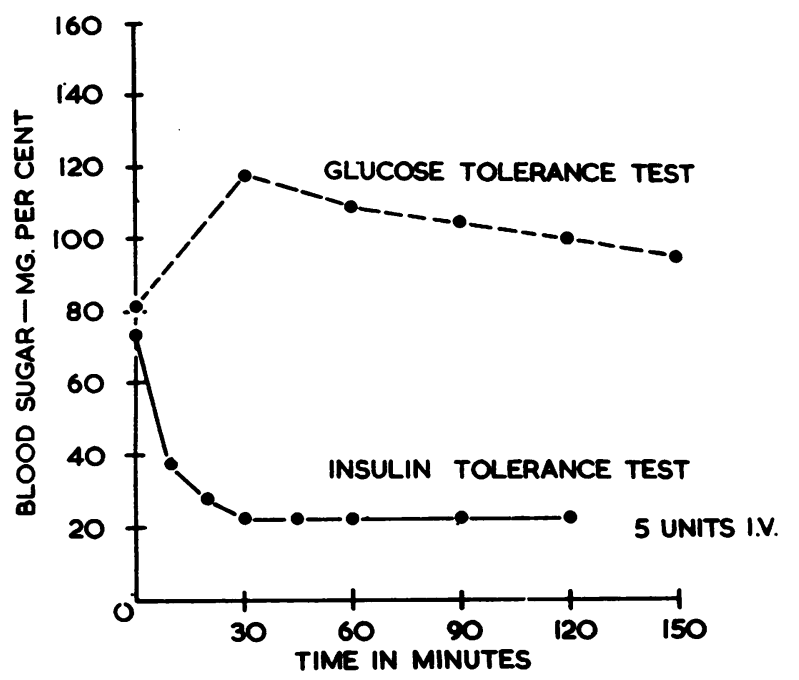

Excretion of 17-ketosteroids : $6.1 \mathrm{mg}$. and $2.6 \mathrm{mg}$./day. Excretion of gonadotrophins : 26 and 14 mouse units/day (Dr. A. M. Hain).

Glucose tolerance and insulin tolerance curves as in Fig. 3.

Blood chemistry :

\begin{tabular}{lr|ll} 
Calcium & $10.5 \mathrm{mg} . \%$ & Globulin & $2.5 \mathrm{~g} . \%$ \\
Inorganic phosphorus & $3.8 \mathrm{mg} . \%$ & Alkaline phosphatase & $8.3 \mathrm{units}$ \\
Cholesterol & $260 \mathrm{mg} . \%$ & & $100 \mathrm{ml}$. \\
Sodium & $335 \mathrm{mg} \%$ & Thymol turbidity & 7.8 units \\
Potassium & $19.2 \mathrm{mg} \% \%$ & & $100 \mathrm{ml}$. \\
Albumin & $3.3 \mathrm{~g} . \%$ & &
\end{tabular}

Progress.-The patient developed attacks of drowsiness, alternating with delusions of persecution and hallucinations. There was no excessive sweating, but a blood sugar estimation during an attack was only $33 \mathrm{mg} . \%$ Intravenous glucose raised the blood sugar level but had only a temporary effect on the clinical picture. Adrenal cortical extracts, salt, and methyl testosterone were also given, with little response. He died on October 18, 1948.

\section{Pathological and Histological Examination}

The body was that of a well-nourished adult male, with almost complete loss of pubic and axillary hair. The only other abnormal naked eye findings, apart from an early bronchopneumonia, were related to the endocrine glands and reproductive organs. The meninges covering the sella-turcica were thickened and adherent, and the pituitary was flattened with a depression on the upper surface. The pituitary stalk was elongated and the tuber cinereum prominent. The adrenals and testes were small. There was no appreciable enlargement of lymphoid tissue.

Pituitary.-The capsule was thickened, showing dense fibrosis with focal infiltration of lymphocytes and plasma cells. There was complete disorganization of the anterior pituitary (Fig. 4), so that only isolated parenchymal cells could be identified. Scattered throughout were granulomatous foci resembling tubercles, consisting of groups of epithelioid cells with surrounding infiltration by lymphocytes and plasma cells. There was no caseation, and some granulomatous foci were healing by fibrosis and hyalinization. There were numerous large, multinucleated, Langhans' giant cells, both in the granulomatous foci and in the cellular infiltration (Fig. 5). Many of these giant cells were much larger than the type seen in tuberculosis, and resembled foreign body 


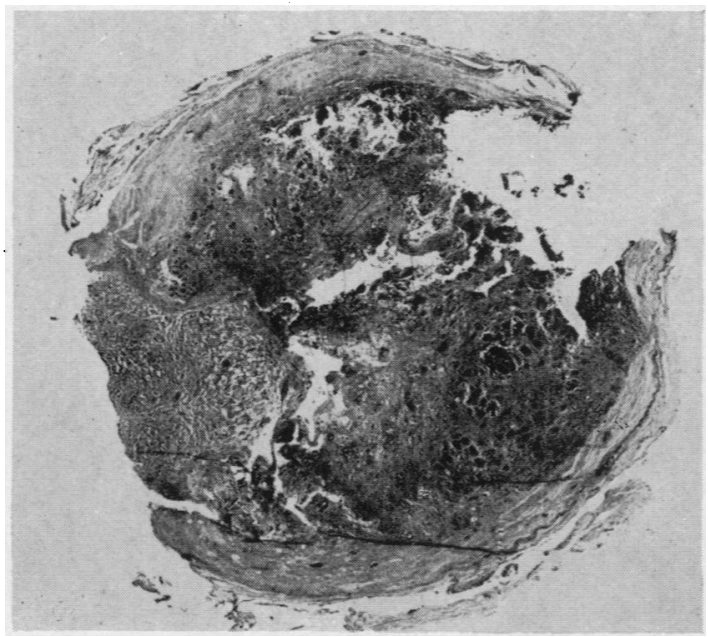

FIG. 4.-Pituitary showing capsular fibrosis and disorganization of anterior lobe. (Haematoxylin and $\operatorname{eosin} \times 6$.)

Fig. 5.-Granulomatous lesions in pituitary, with lymphocytic infiltration and Langhans's giant cells. (Haematoxylin and eosin $\times 100$.)

FIG. 6.-Massive vacuolated giant cell with basophilic inclusions in granulomatous lesion. (Haematoxylin and eosin $x$ 270.)

FIG. 7.-Large vacuole in giant cell filled by refractile crystalline material. (Polarized light. Safranin $\times 270$.)
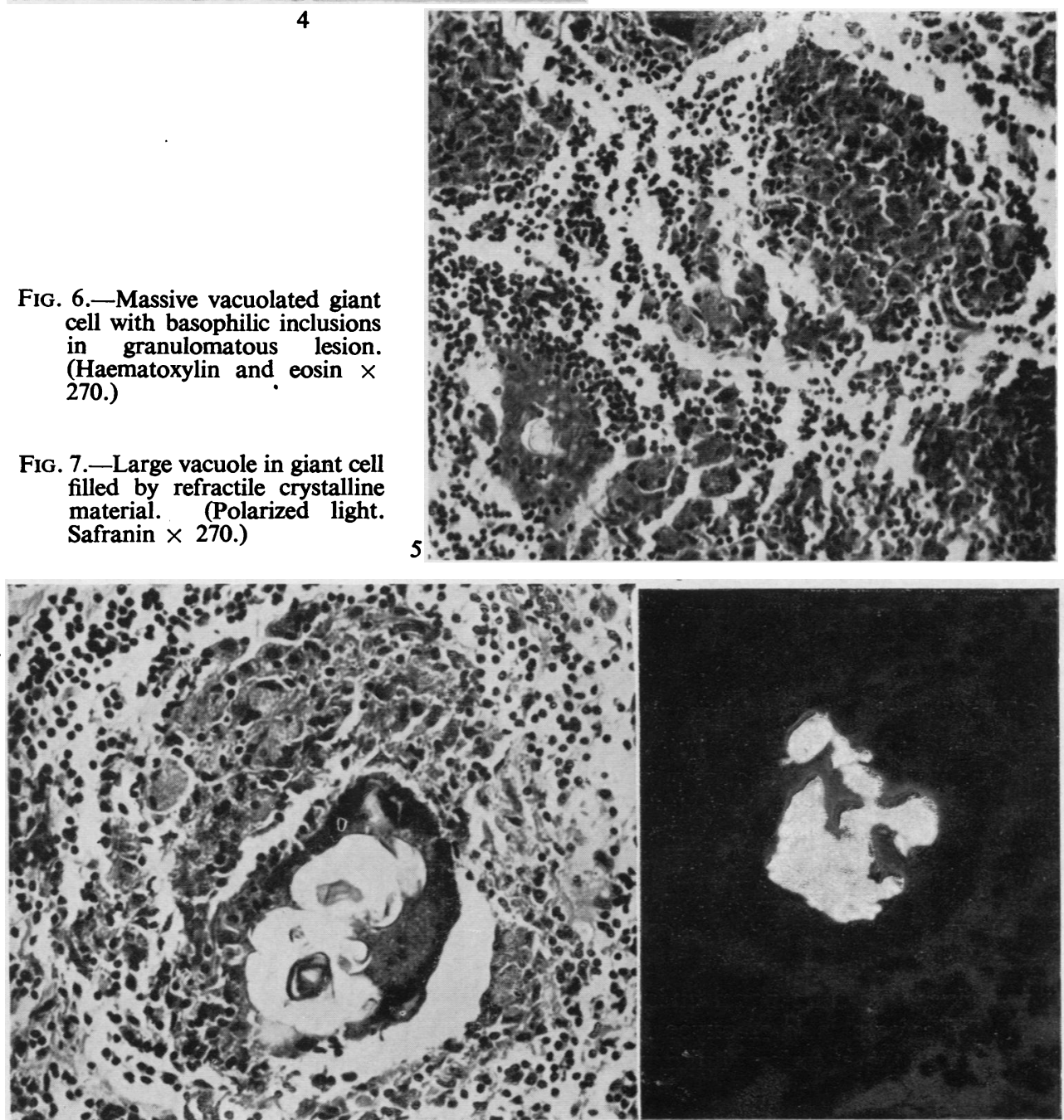
giant cells. Many showed vacuolation and contained fibrillary basophilic material (Fig. 6). In unstained sections, and in sections which had not been treated with acid alcohol, these inclusions were seen, using polarized light, to be embedded in a refractile crystalline mass (Fig. 7). This accounted for the irregular staining of the fibrillary material. Micro-incineration showed that the crystalline material was inorganic, and microchemical tests indicated it to be chiefly calcium. The vacuolation of the giant cells in sections stained by haematoxylin and eosin was thus apparently due partly to the solubility of the crystalline material in acid alcohol, and partly to the material dropping from the section. Many of these giant cells appeared to be formed by the fusion of smaller giant cells. Basophil fibrillary fragments were also seen lying free in the centre of granulomatous foci and in the disorganized gland. Sections stained for spirochaetes and tubercle bacilli were negative. The posterior pituitary was normal except for a few small lymphocytic foci.

Adrenals.-There was marked hypoplasia of the cortex involving all the zones, but there was no fibrous zone replacing the zona reticularis, as noted by Sheehan and Summers (1949) in severe hypopituitarism. The cells showed a normal fat content. Multiple small granulomatous lesions resembling those seen in the pituitary were present in both the cortex and medulla. Small Langhans' giant cells were present, but no massive giant cells with inclusions.

Thyroid.-There were atrophic changes with small acini, areas of fibrosis, and lymphocytic infiltration.

Testes.-There was widespread atrophy of the epithelium of the seminiferous tubules with complete absence of spermatogenesis. The tubules showed hyaline thickening of the basement membrane, and there was a fine intertubular fibrosis with scattered lymphocytes. No interstitial cells could be identified. Numerous thin-walled veins, especially in the rete testis, showed granulomatous foci in the walls just beneath the endothelium. These closely resembled the lesions in the pituitary. A few small Langhans' giant cells were present. Many other vessels showed focal fibrosis suggesting similar healed lesions.

Skin.-The axillary skin showed atrophy of the epithelium and rete pegs, elastosis in the superficial dermis, only an occasional atrophic hair follicle, and complete absence of sebaceous glands. Groups of sweat glands were present, with foci of lymphocytes around the vessels.

Apart from scanty lymphocytic infiltration in the portal tracts in the liver, no changes were noted in the heart, pancreas, spleen, lymph glands, or hypothalamus.

\section{Discussion}

The clinical picture, with marked asthenia, sensitiveness to cold, decrease in libido, loss of pubic and axillary hair, and attacks of hypoglycaemia, is quite characteristic of hypopituitarism. The results of the biochemical investigations support the diagnosis, and will now be briefly discussed, since they are the means of assessing the functional activity of the endocrines. Diminished thyroid activity is indicated by the low basal metabolic rate. The Kepler test, insulin tolerance test, and the excretion of 17-ketosteroids afford some indication of the activity of the adrenal cortex. The positive Kepler test (Robinson, Power, and Kepler, 1941) shows deficiency of the electrolyte regulating hormones of the adrenal cortex, while the marked "hypoglycaemia unresponsiveness" in the insulin tolerance test (Fraser and Smith, 1941) indicates a lack of oxycorticosteroids (and possibly lack of the diabetogenic hormone of the anterior pituitary). The 17-ketosteroid excretion was reduced, but 
higher than that found by most workers (Fraser and Smith, 1941 ; Fraser et al., 1941). Simpson (1948) states that he has had one definite case of hypopituitarism with an excretion of $12 \mathrm{mg}$./day. The gonadotrophin output, as a direct indication of the activity of the anterior pituitary, was within normal limits, in contrast to the low excretion recorded by Klinefelter, Albright, and Griswold (1943). These values indicate biochemically that the hypopituitarism was not severe and was probably of recent onset. Pathologically, the degree of atrophy of the thyroid, adrenal, and testis is not of the advanced type that occurs in long-standing hypopituitarism, and accords with the subacute nature of the pituitary lesion. The extreme disorganization of the anterior pituitary is, however, difficult to reconcile with the normal gonadotrophin output.

Clinically the cause of the pituitary damage was thought to be congenital syphilis. This diagnosis entirely depended on the condition of the eyes and teeth. The ophthalmologist considered the interstitial keratitis to be diagnostic of congenital syphilis. The dental surgeon (Mr. Matheson) stated that the appearance of the left upper central incisor indicated a developmental defect seen in congenital syphilis. However, the Wassermann and Kahn reactions of the blood and cerebrospinal fluid were negative. Congenital syphilis was not established in any of the siblings, and the Wassermann reaction of the mother was negative.

The characteristic features of the pituitary lesion were the multiple granulomatous nodules resembling tubercles, the widespread lymphocytic and plasma cell infiltration, and the many large vacuolated Langhans' giant cells containing basophilic inclusions. This appearance does not suggest a syphilitic process. Lesions of the pituitary caused by syphilis vary from gummatous necrosis (Simmonds, 1914) to diffuse interstitial fibrosis (Good and Newman, 1929; Hirsch, 1922 ; Farquharson and Graham, 1931), and are usually associated with gummatous necrosis in other organs (Sheehan and Summers, 1949).

The pituitary lesion in our case closely resembles that described by Simmonds (1918) in five elderly females in a series of 2,000 necropsies. These patients died from various types of acute and chronic diseases, but there were no symptoms referable to pituitary damage. The lesion was limited to the anterior pituitary, and not found in other organs. Simmonds considered that the process was neither tuberculous nor syphilitic but was a condition sui generis. Sheehan and Summers (1949) have classified a number of similar cases as giant cell granuloma of the anterior pituitary, both in subacute (17 cases) and healed ( 9 cases) stages. Most of the cases occurred in females between the ages of 45 and 65 years. Six of the subacute cases showed similar lesions in the brain and meninges, but otherwise the process appeared localized to the anterior pituitary. They concluded that most cases appeared to be examples of a specific process of unknown aetiology, but a few were said to be syphilitic. These, however, showed little or no evidence of syphilis in other organs. We have reviewed many of these cases of so-called giant cell granuloma, and though several closely resemble our case the evidence for the inclusion of others is rather doubtful.

The histological features of giant cell granuloma are in many ways similar to those of sarcoid. Tillgren (1935) described a male aged 42 years, with typical sarcoid in lymph glands, skin, and bone, who developed diabetes insipidus. The pituitary 
lesion, showing large Langhans' giant cells, with basophilic inclusions, closely resembles our case. Similar features were seen in a female aged 41 years, reported by Kraus (1942). Barber (1945) reported the development of hypopituitarism in a male aged 28 years, with typical clinical evidence of sarcoidosis. Longcope (1941) has remarked that giant cells are not regularly present in sarcoid but are quite common, and are often large and irregular and contain peculiar basophilic inclusions, sometimes suggesting calcified material. These inclusions have been considered by many observers to be characteristic of sarcoidosis. We have seen inclusions, closely resembling those in our case of giant cell granuloma, in a typical case of sarcoidosis which had been followed over a period of 12 years. Schaumann (1941), however, stated that Metchnikoff had observed this type of inclusion body in an ape infected with tuberculosis. Professor Baker has kindly shown us sections of an inguinal node from a girl aged 3 years, who, clinically and radiologically, had tuberculous disease of the right hip joint. This lymph node showed scattered granulomatous tubercles with several large giant cells containing similar refractile basophilic inclusions. While this similarity to sarcoid should be considered, we have no convincing evidence that giant cell granuloma and sarcoid are the same process. Other lesions characteristic of sarcoid are absent in our case. The occurrence of granulomatous lesions in the testis and adrenal does, however, suggest the possibility of a systemic infection, though it is striking that these lesions have only occurred in the adrenal and testis, both of which are subject to a trophic hormone deficiency.

In the recent literature a similar type of lesion was reported by Coleman and Meredith (1940). In a patient with symptoms suggesting a pituitary neoplasm, a mass of tissue was removed surgically, and this histologically resembled hyperplastic tuberculosis or sarcoidosis. Giant cells were present but no inclusions were mentioned. This patient was alive and apparently well three and a half years later, suggesting that the lesion may have been limited to the pituitary region. Glass and Davis (1944) reported a granuloma of the pituitary, associated with panhypopituitarism, in a male aged 54 years. The lungs showed an infiltrative lesion with areas of caseation, and the anterior pituitary was largely replaced by dense scar tissue. The photographs are not helpful in assessing the aetiology, but it seems reasonable to relate the pituitary and lung lesions which appear to be due to either tuberculosis or sarcoid. Letchworth (1924) described a male, aged 16 years, with diabetes insipidus. There was a mass, surrounding the pituitary and optic chiasma, which was described as "tuberculous" but with no evidence of tubercle elsewhere. No histological details are given.

Sheehan and Summers (1949) described the formation of these large giant cells in two cases of " healed giant cell granuloma " and noted the development of central foaminess, followed by vacuolation and finally a clear space sometimes containing basophilic fibrillary inclusions. We consider that in our case the vacuolation in the giant cells was largely an artefact due to the solubility in acid alcohol of the crystalline material enveloping the fibrillary inclusions. This basophilic material has been seen lying free in granulomatous areas and its staining reactions and appearance suggest an origin from the reticular framework of the gland. These fragments are then probably engulfed by giant cells. 
Sheehan and Summers (1949) commented on the possibility that the epithelioid and giant cells of the granulomatous foci might be derived from parenchymal cells, the lesion being analogous to the pseudogranulomatous nodules of the atrophying thyroid. This suggestion is hardly tenable in our case since similar granulomatous lesions were found in the adrenal and testis.

In conclusion our case is best considered as belonging to the group of giant cell granulomas of the anterior pituitary of unknown aetiology. Whether this is a specific disease process cannot be decided on the present evidence. Our case is of interest since it clearly shows that the process is not strictly localized to the anterior pituitary.

\section{Summary}

A case of hypopituitarism in a male with clinical evidence of congenital syphilis is recorded.

The lesion in the anterior pituitary was a giant cell granuloma.

The aetiology of the condition has been discussed.

The presence of additional lesions in the adrenal and testis suggests the possibility of a systemic infection.

We wish to thank Dr. C. S. D. Don and Dr. F. Janus for permission to publish this case, Professor H. L. Sheehan for his invaluable opinion, and Professor S. L. Baker for helpful advice and criticism. Our thanks are also due to Mr. H. Varley, M.Sc., for the biochemical investigations, Dr. A. M. Hain for the gonadotrophin estimations, Mr. J. Kilshaw (Department of Medical Photography) for the photographs, and Mr. F. Ward for the photomicrographs.

\section{REFERENCES}

Barber, H. W. (1945). Proc. R. Soc. Med., 39, 92.

Coleman, C. C., and Meredith, J. M. (1940). Arch. Neurol. Psychiat., Chicago, 44, 1076.

Escamilla, R. F., and Lisser, H. (1942). J. clin. Endocrinol., 2, 65.

Farquharson, R. F., and Graham, D. (1931). Trans. Ass. Amer. Phys., 46, 150.

Fraser, R. W., Forbes, A. P., Albright, F., Sulkowitch, H., and Reifenstein, E. C. (1941). J. clin. Endocrinol., 1, 234.

- and Smith, P. H. (1941). Quart. J. Med., n.s., 10, 297.

Glass, S. J., and Davis, D. S. (1944). J. clin. Endocrinol., 4, 489; 611.

Good, T. S., and Newman, K. O. (1929). Lancet, 1, 765.

Hirsch, S. (1922). Dtsch. Arch. klin. Med., 140, 323.

Klinefelter, H. F., Albright, F., and Griswold, G. C. (1943). J. clin. Endocrinol., 3, 529.

Kraus, E. J. (1942). J. Lab. clin. Med., 28, 140.

Letchworth, T. W. (1924). Brit. med. J., 1, 1127.

Longcope, W. T. (1941). J. Amer. med. Ass., 117, 1321.

Robinson, F. J., Power, M. H., and Kepler, E. J.(1941). Proc. Mayo Clin., 16, 577.

Schaumann, J. (1941). Acta med. scand., 106, 239.

Sheehan, H. L. (1948). Proc. R. Soc. Med., 41, 187.

and Summers, V. K. (1949). Quart. J. Med., n.s., 18, 319.

Simmonds, M. (1914) quoted by Jaffé, R. (1922). Frankfurt. Z. Path., 27, 324.

- (1918). Virchows Arch., 223, 281.

Simpson, S. L. (1948). Proc. R. Soc. Med., 41, 192.

Tillgren, J. (1935). Brit. J. Derm. Syph., 47, 223. 